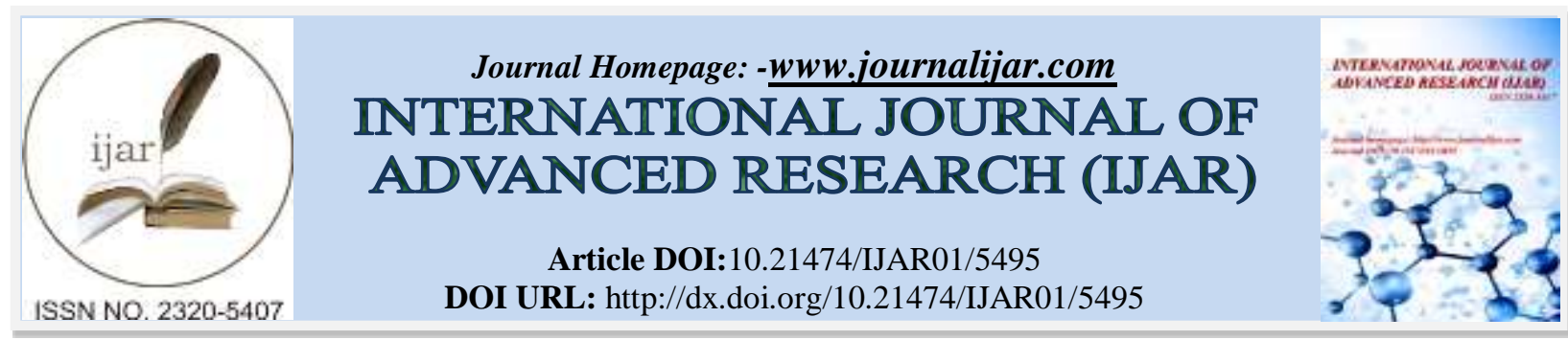

RESEARCH ARTICLE

\title{
MATRIX METALLOPROTEINASES AND CORONARY ARTERY ECTASIA.
}

PieroLevantino, Massimo Raspanti, Salvatore Evola, Giuseppina Novo, Giovanna Evola and Salvatore Novo. University Hospital P. Giaccone Department Of Cardiology, Palermo, Italy.

\section{Manuscript Info}

Manuscript History

Received: 22 July 2017

Final Accepted: 24 August 2017

Published: September 2017

Key words:-

Coronary artery ectasia, Matrix

Metalloproteinases, Atherosclerosis.

\section{Abstract}

Background: Coronary artery ectasia is the abnormal dilatation of one or more coronary segments. Although the pathogenetic mechanisms underlying CAE are largely unknown, it seems that some of the extracellular matrix degrading enzymes such as matrix metalloproteinases (mmps) can play an important role in the development of this condition. The aim of our study was to evaluate the relationship between MMP-9 and the development of CAE as well as the role played by the inflammatory process in this condition.

Materials And Methods: In our retrospective study we have enrolled a series of 79 patients: 47 presented, on coronary angiography, focal or diffuse ectasia of coronary arteries (cases), 32 had a free coronary tree or without hemodynamically significant stenosis (controls). All patients were subjected to blood sampling for the dosage of MMP-9 and Creactive protein (CRP).

Results: In our study we found that the most involved coronary artery in CAE was the right coronary artery. Serum levels of MMP-9 were higher in the patients with CAE $(5.011 \mathrm{mcg} / \mathrm{ml}$ vs. $3.93 \mathrm{mcg} / \mathrm{ml}, \mathrm{p}=$ $0,07)$ although not statistically significant, in direct proportion to the number of involved vessels $(\mathrm{p}=0.025)$. Serum CRP levels were higher in patients with CAE (5.12 mg / dl vs. $2.18 \mathrm{mg} / \mathrm{dl}, \mathrm{p}=0.4)$ although not statistically significant, in direct proportion to the number of involved vessels $(\mathrm{p}=0.001)$.

Conclusions: We found a possible relationship between elevated levels of MMP-9 and CAE, as well as the relationship between levels of MMP-9 and severity of the CAE. Furthermore we found a possible relationship between elevated CRP levels and CAE and there was a directly proportional relationship between the increase of CRP and extension of the CAE.

Copy Right, IJAR, 2017,. All rights reserved.

\section{Introduction:-}

Coronary artery ectasia (CAE) is the abnormal dilatation of one or more coronary segments. A vessel is considered to be ectasicwhen its diameter is $\geq 1.5$ times greater than that of the intact adjacent vascular segment $[1,2]$. CAE is nowdays classified in four different types [3]:

Tipe I, diffuse ectasia of two or three vessels;

Tipe II, diffuse disease in one vessel and localised disease in another vessel;

Corresponding Author:-LevantinoPiero.

Address:-University Hospital P. Giaccone Department Of Cardiology, Palermo, Italy. 
Tipe III, diffuse ectasia of one vessel only;

Tipe IV, localized segmental ectasia.

The etiopathogenesis of CAE is not yet fully known. Several hypotheses have been formulated including an abnormal extracellular matrix degradation by matrix metalloproteinases (MMPs), proteolytic enzymes, part of a large family of proteases known as a zinc-dependent endopeptidase. MMPs have been implicated in several physiological processes such as fetal development, wound healing, reproduction [4] as well as in pathological processes such as tumor invasion, skin and lung diseases and, according to some recent studies, even in the genesis of CAE $[5,6]$.

Aim of our study was to evaluate the correlation between serum levels of a specific metalloproteinase, MMP-9, and the presence of CAE as well as the role played by the inflammatory process in this condition evaluating the possible correlation between $\mathrm{C}$-reactive protein (CRP) values and CAE.

\section{Materials and Methods:-}

In our retrospective study we evaluated 1116 coronary angiography performed in the Hemodynamic and Interventional Cardiologyof the University Hospital "P. Giaccone"of Palermo between July 2015 and August 2016. CAE was found in 63 patients (CAE prevalence of 5,6\%)

The population recruited (79 patients), according to the angiographic findings, has been divided into two groups:

\section{Group 1:-}

Patients (47) with CAE, focal or diffuse, with or without hemodynamically significant stenosis, cases (16 patients have not been recruited because they didn't give their consent to participate in our study)

\section{Group 2:-}

Patients (32) with normal coronary arteries or without hemodynamically significant stenosis $(<50 \%$ diameter reduction), controls. Exclusion criteria for these patients were a positive history for previous coronary angioplasty or previous surgery of aorto-coronary bypass.

For each group we have recorded the demographic characteristics (age and gender), the most common risk factors for cardiovascular diseases (hypertension, dyslipidemia, diabetes mellitus, family history of cardiovascular disease, smoking) and the clinical indication for coronary angiography.

Digital angiographic images were acquired using an angiography Philips Integris 2000 or a Siemens Artis Zee, at the rate of 12.5 frames / sec.

Based on the coronary angiography we have evaluated:

1. What were the vessels most frequently affected by ectasia and, in case of stenosis, if the aneurysm interested or not the culprit lesion;

2. The number of dilated coronary arteries;

3. The percentage of patients with focal disease (ectasia involving a small segment of the coronary artery) or diffuse (involvement of a broad segment or involvment of the entire coronary artery);

4. The modality of revascularization (Surgical or endovascular revascularization).

All patients, about a month after discharge, were subjected to a venous blood sample for the dosage of MMP-9 and PCR.

The samples were centrifuged at $4^{\circ} \mathrm{C}$ for 10 minutes and the serum separated in aliquots and frozen at $-20^{\circ} \mathrm{C}$. The dosage of metalloproteinases was performed using the kit Human matrix metalloproteinase-9 (MMP-9) ELISA (RayBioPantec-Germany).

The kit that we used was a direct sandwich ELISA (Enzyme-lynkedimmuno-sorbent assay) that included a plate with 96 wells coated with polyclonal antibody specific metalloproteinases.

The antibody-antigen complex was highlighted by the addition of biotinylated second antibody which formed a triple layer that gives it the name to this test. The addition of streptavidin-biotin-peroxidase complex with its 
substrate for the enzyme, is then translated into the formation of a blue color in the individual wells that turned yellow after the addition of acidic stop solution.

The chromogenic reaction formed was subsequently measured by a plate reader (DAS plate reader) and the intensity was proportional to the amount of antigen present in the sample and captured by the plate.

For the evaluation of the collected data, we used the Student's t-tests, ANOVA test (Analysis of Variance test) and ROC curves (Receiver-Operating Characteristics).

\section{Result:-}

In our study, we recruited a series of 79 patients. In 47 patients (cases) we have documented CAE focal or diffuse, in 32 patients (controls) a free coronary tree or without hemodynamically significant stenosis.

Patients with coronary artery ectasia had an average age of 63.9 years of which $85.1 \%$ were male. Patients with normal coronary arteries had an average age of 62.2 years of which $71.8 \%$ were male. For both groups of patients we evaluated the traditional cardiovascular risk factors, which we found to be overlapping. In particular, the majority of patients had arterial hypertension $(85.1 \%$ cases vs. $75 \%$ controls) and dyslipidemia $(70.2 \%$ cases vs. $65.7 \%$ controls). Diabetes mellitus was instead underreprensented in our population, $25.5 \%$ cases vs. $28.1 \%$ controls (Table 1).

In both groups the predominant indication for coronary angiography was angina,followed, in the case group, by the acute myocardial infarction without persistent ST-segment elevation or NSTEMI (about a third of the enrolled population). Only $15 \%$ of patients had an acute myocardial infarction with persistent ST-segment elevation or STEMI, while a minority of cases (8\%), performed coronary artery evaluation in anticipation of a planned cardiac surgery, pre-CCH (Table 2).

$34 \%$ of patients undergoing coronary angiography had diffuse ectasia, the remaining $66 \%$ a focal ectasia.

The most involved coronary artery in the contest of diffuse ectasia were the right coronary artery and left anterior descending, followed by circumflex. In the group of patients with focal ectasia, the involvement of the right coronary artery was dominant. The involvement of the anterior descending and circumflex was minor and even rarer common trunk of the left coronary artery (Table 3).

In our study we found serum levels of MMP-9 in patients with CAE higher than in patients with normal coronary arteries, $5.011 \mathrm{mcg} / \mathrm{ml}$ vs. $3.93 \mathrm{mcg} / \mathrm{ml}, \mathrm{p}=0.07$ (Figure 1).

We also found a statistically significant increase $(\mathrm{p}=0.025)$ in serum levels of MMP-9 in direct proportion to the number of vessels involved in the ectatic process (Figure 2).

Serum levels of MMP-9 in patients with diabetes mellitus were found to be significantly lower than patients without diabetes mellitus, $\mathrm{p}=0.05$ (Figure 3).

Finally, serum CRP levels were higher in patients with CAE, $5.12 \mathrm{mg} / \mathrm{dl} \mathrm{vs} 2.18 \mathrm{mg} / \mathrm{dl}(\mathrm{p}=0.4)$, in a direct proportion to the number of involved vessels, $p=0.001$ (Figure 4) .

In our analysis we found that, in case of diffuse coronary involvement, CRP levels were about 20 times (average CRP levels $=10.54 \mathrm{mg} / \mathrm{dl}$ ) the normal values (v.n. $<0.6 \mathrm{mg} / \mathrm{dl}$ ).

Table 1:- Percentage distribution of cardiovascular risk factors in the two groups of patients. (CVD:cardiovascular disease).

\begin{tabular}{|c|c|c|c|c|c|}
\hline & HYPERTENSION & DYSLIPIDEMIA & $\begin{array}{c}\text { FAMILY HISTORY } \\
\text { OF CVD }\end{array}$ & $\begin{array}{c}\text { DIABETES } \\
\text { MELLITUS }\end{array}$ & SMOKE \\
\hline PATIENTS CAE & $\mathbf{8 5 , 1 \%}$ & $\mathbf{7 0 , 2 \%}$ & $\mathbf{3 6 , 2 \%}$ & $\mathbf{2 5 , 5 \%}$ & $\mathbf{4 8 , 9 \%}$ \\
\hline PATIENTS CONTROL & $\mathbf{7 5 \%}$ & $\mathbf{6 5 , 7 \%}$ & $\mathbf{5 0 \%}$ & $\mathbf{2 8 , 1 \%}$ & $\mathbf{6 2 , 5 \%}$ \\
\hline
\end{tabular}


Table 2:- Clinical indications for the execution of coronary angiography.

\begin{tabular}{|c|c|c|c|c|c|}
\hline & ANGINA & STEMI & NSTEMI & PRE-CCH & OTHER \\
\hline PATIENTS CAE & $45 \%$ & $15 \%$ & $\mathbf{2 8 \%}$ & $\mathbf{8 \%}$ & $\mathbf{4 \%}$ \\
\hline PATIENTS CONTROL & $62 \%$ & $\mathbf{0 \%}$ & $\mathbf{1 0 \%}$ & $\mathbf{1 2 \%}$ & $16 \%$ \\
\hline
\end{tabular}

Table 3:- Distribution of CAE for single vessel in its two forms, focal or diffuse.

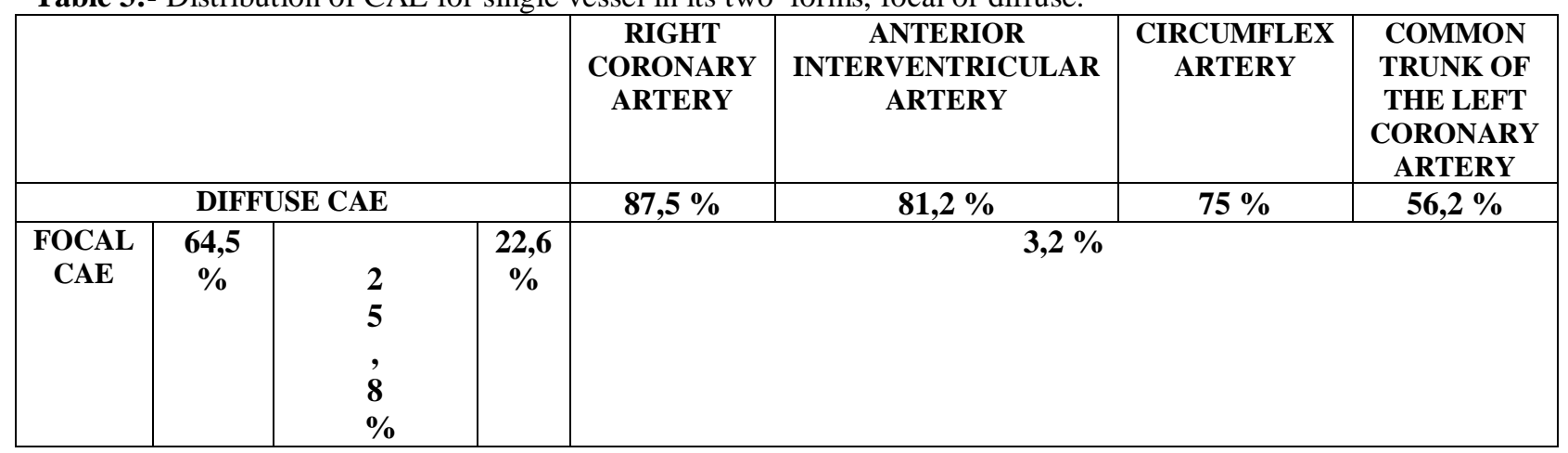

\section{FIGURE}

Figure 1 - Levels of MMP-9 in the patients with normal coronary arteries compared to the patients with coronary artery ectasia; $p=0.07$.

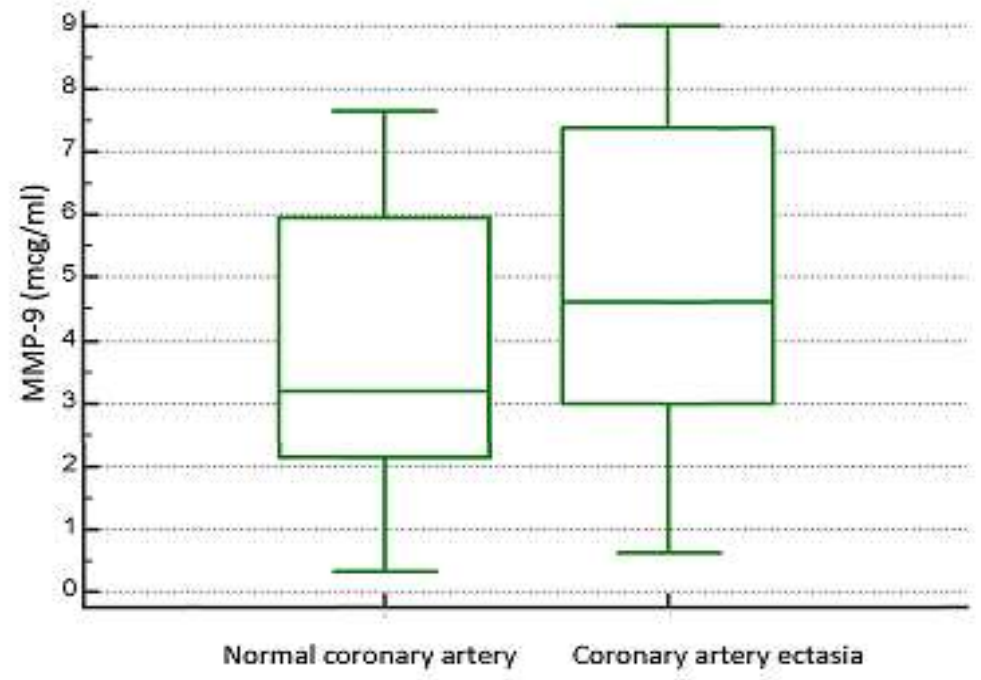


Figure 2 - Increase of MMP-9 levels in relation to the number of vessels involved in the ectatic process; $p=0.025$.

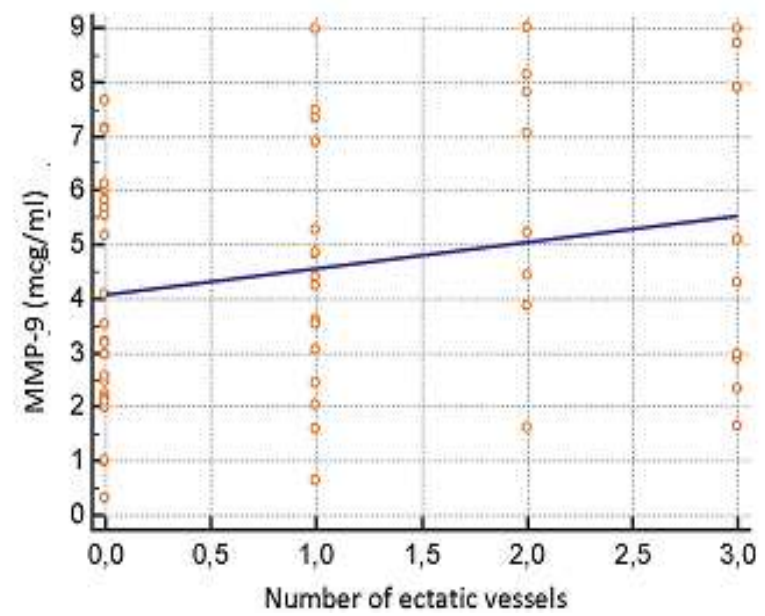

Figure 3- Levels of MMP-9 in non-diabetic and diabetic patients; $p=0.05$.

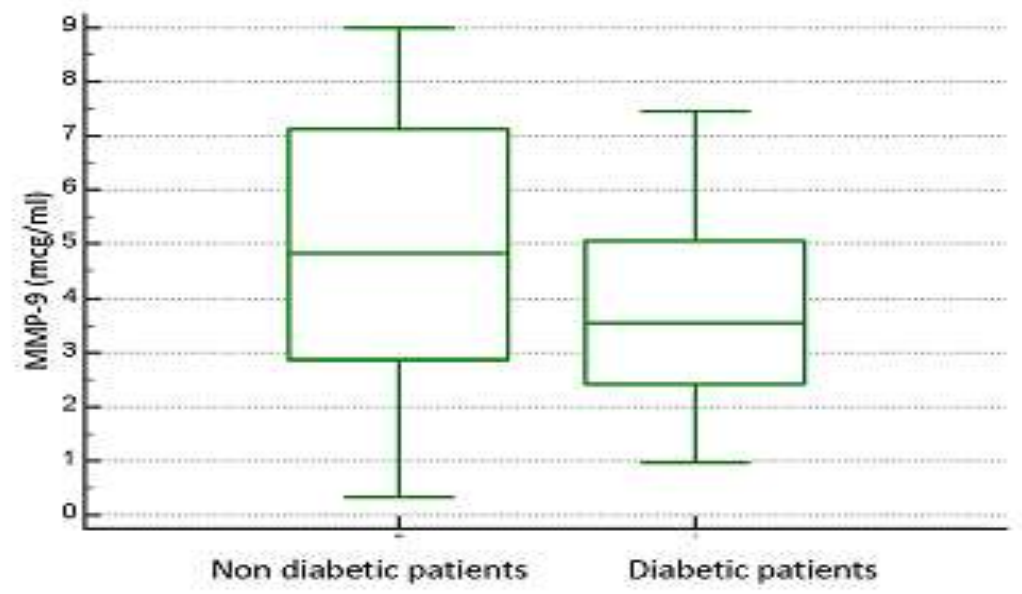

Figure 4 - Levels of CRP in relation to the number of vessels involved in the ectatic process; $p=0.001$.

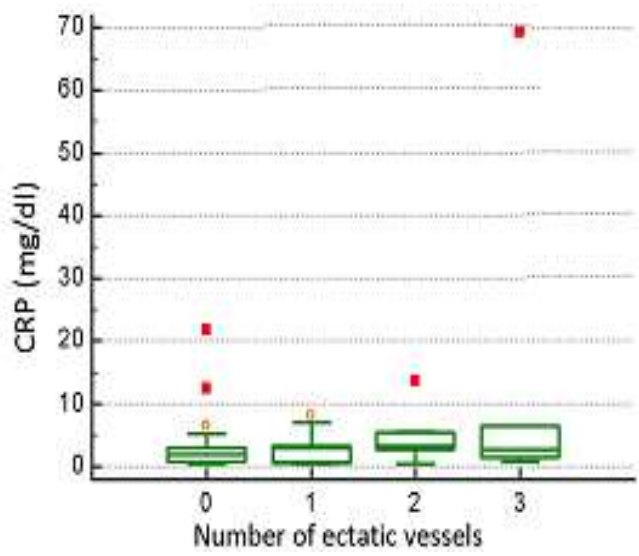




\section{Discussion:-}

Coronary artery ectasia is a common condition among the population whose clinical significance has only recently been recognized. Epidemiological data extrapolated from different studies allow us to calculate a prevalence of CAE between $1.4 \%$ and $7.4 \%$ of patients undergoing coronary angiography [2,7] with a higher prevalence in the men, in according to our study [8,9]. The average age, furthermore, was comparable, at the time of diagnosis, both in the cases and in the controls.

The common cardiovascular risk factors were widely represented in the population with CAE, like high blood pressure that was present in $85.1 \%$ of the patients. With regard to diabetes mellitus we observed an inverse correlation with CAE according to the data of the literature: despite diabetes mellitus is an important risk factor for atherosclerosis, it is poorly represented in the population of patients with coronary aneurysms, probably for his role promoting a negative type remodeling rather than expansive [9-12].

We found isolated CAE only in $17 \%$ of cases while $83 \%$ of cases was associated with coronary artery stenosis. This finding agrees with the results published in several previous studies, in which it has been widely shown that CAE co-exists with CAD approximately in $85 \%$ of cases [3,13-17]. The right coronary artery was the most involved artery in the coronary artery ectasia followed by the anterior descending artery and the circumflex artery [2, 13, 18, 19]. Much less, in terms of percentage, the interest of the common trunk of the left coronary artery.

The coronary artery ectasia can have a variable clinical presentation. It is often an occasional finding revealed in the coronary angiography or after the occurrence of angina pectoris or acute coronary syndrome. In fact there is an appreciable incidence of myocardial infarction and angina pectoris in patients with CAE [17,20] and probably the pathophysiological basis that explaine the onset of ischemic events resides in alterations of coronary flow. The slow flow or even static inside the dilated segment can result in the activation of platelet, coagulation cascade and promote thrombus formation $[2,21,22]$.

In our study, the predominant indication for coronary angiography was angina (45\%) and NSTEMI (28\%). Only $15 \%$ of patients with CAE had a transmural infarction, while a minority of subjects performed the coronary evaluation in anticipation of a planned heart surgery.

A pathogenetic role in the development of CAE seems to be played by the extracellular matrix (ECM) and by the enzymes involved in its remodeling. Among these, an important role was attributed to MMPs [1, 2, 19, 23, 24] that determine, in response to biochemical and local hemodynamic insults, abnormal extracellular matrix degradation promoting an exuberant expansive remodeling of the vascular wall and thus the development of CAE [25].

In particular MMPs, proteolytic enzymes of a large family of proteases, the zinc-dependent endopeptidase, are mainly produced by connective tissue cells and secreted into the extracellular matrix, dynamic structure and in continuous regeneration. Since 1962, when Gross and Lapiere discovered the first member of this family (in the context of a study about amphibian tissues) [26] at least 26 MMPs have been identified [1]. They are involved in physiological processes such as the fetal development, wound healing, reproduction [4] and in pathological processes such as the invasion of cancer cells, atherosclerosis, skin and lung diseases [5,6].

Furthermore, MMPs through the proteolysis of extracellular matrix proteins, along with decrease in the serum levels of tissue inhibitors of MMPs (TIMPs) [2], can be involved in the development of aortic aneurysms [23]. In our population, in line with the present literature, we found, in patients with CAE, levels of MMP-9 higher than patients with normal coronary arteries, although not statistically significant; we also noticed an increase, statistically significant, in the levels of MMP-9 in direct proportion to the number of aneurysmal vessels.

Finally, we have focused on the role played by inflammation in the genesis of the aneurysmal process, as suggested in several studies in literature [21, 27-30]. Specifically, we measured in all patients the serum levels of C-reactive protein and we found that its values were higher in patients with CAE compared with those who had normal coronary arteries; furthermore there was an increase in CRP values in direct proportion to the number of vessels involved from ectasia, thus confirming the hypothesis that the degree of inflammation is higher in patients with diffuse ectasia compared to the focal ectasia. These results are consistent with findings from Sarli et al. [27]; these authors have shown that the neutrophils / lymphocytes ratio, marker of inflammation, is higher in patients with isolated CAE and that it is correlated with the severity of the pathology ectasiante. Ammar et al. [28] furthermore 
found higher levels of CRP in patients with CAE than patients with CAD and compared to subjects with normal coronary arteries according to a study by Turhan et al. [29] in which plasma levels of ICAM-1, VCAM-1 and Eselectin were found higher in patients with isolated CAE than patients with CAD or normal coronary arteries, suggesting the presence of a more severe and extended chronic inflammation in the coronary circulation of these patients.

The frequent coexistence between CAE and CAD and some common histopathological aspects to the two conditions have led to the hypothesis, especially in the past, that the coronary artery ectasia could be a possible manifestation of atherosclerosis. However, today, various evidence, including the inverse correlation between diabetes mellitus, age and CAE, as well as higher levels of CRP, MMPs in the CAE than the CAD, the geater involvement of the right coronary artery in the $\mathrm{CAE}$ compared the anterior interventricular artery in $\mathrm{CAD}$, lead us to think that the CAE could be a separate entity compared to coronary atherosclerosis, despite it determines similar symptoms and harmful insults to myocardial tissue [25].

\section{Conclusions:-}

Although the pathogenetic mechanisms underlying the CAE are largely unknown, it seems that some of extracellular matrix degrading enzymes as MMPs and some interleukins play an important role in the development of CAE. We found a possible relationship between elevated levels of MMP-9 and CAE, as well as the relationship between levels of MMP-9 and severity of the CAE. Furthermore we found a possible relationship between elevated CRP levels and $\mathrm{CAE}$ and there was a directly proportional relationship between the increase of CRP and extension of the CAE.

\section{Conflict Of Interest:-}

The authors declare that they have no conflict of interest. All authors concur with the submission and none of the data is under consideration for publication elsewhere.

\section{Ethical Approval:-}

All procedures performed in studies involving human participants were in accordance with the ethical standards of the institutional and/or national research committee and with the 1964 Helsinki declaration and its later amendments or comparable ethical standards.

\section{Informed Consent:-}

Informed consent was obtained from all individual participants included in the study.

\section{References:-}

1. Liu R, Chen L, Wu W, Chen H, Zhang S (2016). Extracellular matrix turnover in coronary artery ectasia patients. Heart Vessels ; 31:351-359.

2. Eitan A, RoguinA (2016). Coronary artery ectasia: new insights into pathophysiology, diagnosis and treatment. Coronary Artery Disease; 27(5):420-8

3. Markis JE, Joffe CD, Cohn PF, Feen DJ, Herman MV, Gorlin R (1976). Clinical significance of coronary arterial ectasia. Am J Cardiol ;37:217-222.

4. Airola K, Ahonen M, Johansson N, Heikkilä P, Kere J, Kähäri VM, Saarialho-Kere UK(1998). Human TIMP-3 is expressed during fetal hair development, hair growth cycle and cancer progression. J HistochemCytochem ;46:1-11

5. Uitto VJ, Airola K, Vaalamo M, Johansson N, Putnins EE, Firth JD, Salonen J, López-Otín C, Saarialho-Kere U, Kähäri VM (1998). Collagenase-3 (MMP-13) expression is indued in oral mucosa epithelium during chronic inflammation. Am J Pathol ;152:1489-1499

6. Finkelstein A, Michowitz Y, Abashidze A, Miller H, Keren G, George J (2005). Temporal association between circulating proteolytic, inflammatory and neurohormonal markers in patients with coronary ectasia. Elsevier, Atherosclerosis ; 179:353

7. Dahhan A (2015). Coronary Artery Ectasia in Atherosclerotic Coronary Artery Disease, Inflammatory Disorders, and Sickle Cell Disease. Cardiovascular Therapeutics ; 33:79-88

8. Giannoglou GD, Antoniadis AP, Chatzizisis YS, Damvopoulou E, Parcharidis GE, Louridas GE (2006). Prevalence of ectasia in human coronary arteries in patients in northern Greece referred for coronary angiography. Am J Cardiol ;98:314-8 
9. Pinar Bermúdez E, LópezPalop R, Lozano Martínez-Luengas I, Cortés Sánchez R, Carrillo Sáez P, Rodríguez Carreras R, PicóAracil F, Valdés Chávarri M (2003). Coronary ectasia: prevalence, clinical and angiographic characteristics. Revista Espanola De Cardiologia, 56:473-479

10. Androulakis AE, Andrikopoulos GK, Kartalis AN, Stougiannos PN, Katsaros AA, Syrogiannidis DN, Tapanlis EN, Stefanadis C, Kallikazaros IE (2004). Relation of coronary artery ectasia to diabetes mellitus. Am J Cardiol; 93:1165-1167

11. Yetkin E, Waltenberger J (2007). Novel insight into an old controversy: is coronary artery ectasia a variant of coronary atherosclerosis? Clin Res Cardiol; 96:331-339

12. Blanchard JF, Armenian HK, Friesen PP (2000). Risk factors for abdominal aortic aneurysm: results of a casecontrol study. Am J Epidemiol ; 151:575-583

13. Swaye PS, Fisher LD, Litwin P, Vignola PA, Judkins MP, Kemp HG, Mudd JG, Gosselin AJ (1983)

14. Aneurysmal coronary artery disease. Circulation ; 67: 134-138

15. Antoniadis AP, Chatzizisis YS, Giannoglou GD (2008). Rewiew of Pathogenetic Mechanisms of coronary ectasia. International Journal of Cardiology; 130: 335-343

16. Krüger D, Stierle U, Herrmann G, Simon R, Sheikhzadeh A (1999). Exercise-induced myocardial ischemia in isolated coronary artery ectasias and aneurysms ('dilated coronopathy'). J Am CollCardiol; 34:1461-1470.

17. Akyürek O, Berkalp B, Sayin T, Kumbasar D, Kervancioğlu C, Oral D (2003). Altered coronary flow properties in diffuse coronary artery ectasia. Am Heart J;145:66-72.

18. V. P. Demopoulos, C. D. Olympios, C.N. Fakiolas, E. G. Pissimissis, N. M. Economides, E. Adamopoulou, S. G. Foussas and D. V. Cokkinos (1997). The natural history of aneurysmal coronary artery disease. Heart ; 78:136-141

19. Mavrogeni S (2010). Coronary artery ectasia: From Diagnosis to Treatment. Hellenic Journal of Cardiology; 51: 158-163

20. Lamblin N, Bauters C, Hermant X, Lablanche JM, Helbecque N, Amouyel P (2002). Polymorphisms in the promoter regions of MMP-2, MMP-3, MMP-9 and MMP-12 genes as determinants of aneurismal coronary artery disease. J Am Coll Cardiol;40:43-48

21. Baman TS, Cole JH, Devireddy CM, Sperling LS (2004). Risk factors and outcomes in patients with coronary artery aneurysms. Am J Cardiol;93:1549-1551

22. Brunetti ND, Salvemini G, Cuculo A, Ruggiero A, De Gennaro L, Gaglione A, Di Biase M (2014). Coronary artery ectasia is related to coronary slow flow and inflammatory activation. Atherosclerosis; 233:636-640

23. Kuramochi Y, Ohkubo T, Takechi N, Fukumi D, Uchikoba Y, Ogawa S (2000). Hemodynamic factors of thrombus formation in coronary aneurysms associated with Kawasaki disease. PediatrInt; 42:470-475.

24. Carrell TW, Burnand KG, Wells GM, Clements JM, Smith A (2002). Stromelysin-1 (matrix metalloproteninase-3) and tissue inhibitor of metalloproteinase-3 are overexpressed in the wall of abdominal aortic aneurysms. Circulation ;105:477-482

25. Dogan A, Tuzun N, Turker Y, Akcay S, Kaya S, Ozaydin M (2008). Matrix metalloproteinases and inflammatory markers in coronary artery ectasia: their relationship to severity of coronary artery ectasia. Coron Artery Dis; 19:559-563

26. Dendramis G, Paleologo C, Lo Presti A, Piraino D, Lo Greco V, Grassedonio E, La Grutta L, Midiri M, Assennato P, Novo S (2014). Coronary artery ectasia: etiopathogenesis, diagnosis and treatment. G ItalCardiol (Rome);15(3):161-9.

27. Gross J, Lapiere CM (1962). Collagenolytic activity in amphibian tissue: a tissue culture assay. Physiol ,48:1014-1022

28. Sarli B, Baktir AO, Saglam H, Arinc H, Kurtul S, Sivgin S, Akpek M, Kaya MG (2014). Neutrophil-tolymphocyte ratio is associated with severity of coronary artery ectasia. Angiology;65:147-151.

29. W. Ammar, M. Kappary, Y. Baghdady, M. Shehata (2014). Matrix metalloproteinase-9 (MMP9) and high sensitivity $\mathrm{C}$ - reactive protein (hs-CRP) in coronary artery ectasia.The Egyptian Heart Journale, Volume 66, Issue 1, Suplement .

30. Turhan H, Erbay AR, Yasar AS, Aksoy Y, Bicer A, Yetkin G, Yetkin E (2005). Plasma soluble adhesion molecules; intercellular adhesion molecule-1, vascular cell adhesion molecule-1 and E-selectin levels in patients with isolated coronary artery ectasia. Coronary Artery Dis; 16:45-50

31. Zhao L, Moos MP, Gräbner R, Pédrono F, Fan J, Kaiser B, John N, Schmidt S, Spanbroek R, Lötzer K, Huang L, Cui J, Rader DJ, Evans JF, Habenicht AJ, Funk CD (2004). The 5-lipoxygenase pathway promotes pathogenesis of hyperlipidemia-dependent aortic aneurysm. Nat Med;10:966-973. 